\title{
Correction to: Leachability of radium-226 from industrial phosphogypsum waste using some simulated natural environmental solutions
}

\author{
E. M. El Afifi ${ }^{1}$ M. Khalil ${ }^{1} \cdot$ Y. F. El-Aryan ${ }^{1,2}$
}

Published online: 19 January 2019

๑) Springer-Verlag GmbH Germany, part of Springer Nature 2019

\section{Correction to: Environmental Earth Sciences (2018) 77:94 https://doi.org/10.1007/s12665-018-7277-x}

In the original publication, the university name of the second affiliation is incorrect. The correct affiliation is Chemistry Department, College of Sciences, University of Bisha, Bisha, Saudi Arabia.

Publisher's Note Springer Nature remains neutral with regard to jurisdictional claims in published maps and institutional affiliations.

The original article can be found online at https://doi.org/10.1007/ s12665-018-7277-x.

E. M. El Afifi

em_afifi1968@yahoo.com; elsayed.m.afifi@eaea.org.eg

1 Hot Laboratories and Waste Management Center (HLWMC), Egyptian Atomic Energy Authority (EAEA), Cairo 13759, Egypt

2 Chemistry Department, College of Sciences, University of Bisha, Bisha, Saudi Arabia 